\title{
CONVERGENCE ANALYSIS OF ENVIRONMENTAL EFFICIENCY FROM THE PERSPECTIVE OF ENVIRONMENTAL REGULATION: EVIDENCE FROM CHINA
}

\author{
Suling $\mathrm{FENG}^{1}$, Haoyue $\mathrm{WU}^{2}$, Guoxiang $\mathrm{LI}^{3 \star}$, Liping $\mathrm{LI}^{4}$, Wenting $\mathrm{ZHOU}^{5}$ \\ ${ }^{1,2}$ School of Business, University of Jinan, 250022 Shandong, China \\ ${ }^{3,5}$ School of Public Economics and Administration, Shanghai University of Finance and Economics, \\ 200433 Shanghai, China \\ ${ }^{4}$ College of Business, Shanghai University of Finance and Economics, 200433 Shanghai, China
}

Received 21 October 2019; accepted 13 July 2020

\begin{abstract}
The aim of this paper is to analyze the impact of environmental regulation on regional environmental efficiency convergence using the fixed effects model and threshold regression model. The results show that the differences in environmental efficiency have a convergence trend in China, as well as in the eastern, central and western regions. The effect of environmental regulation on regional environmental efficiency is inhibition first and then promotion, research and development investment and outward foreign direct investment have a positive transmission effect; when environmental regulation intensity exceeds a certain threshold, the growth rate of environmental efficiency in the central and western regions will be significantly higher than that in the eastern regions.
\end{abstract}

Keywords: environmental regulation, environmental efficiency, outward foreign direct investment, convergence.

JEL Classification: Q51, R42.

\section{Introduction}

Environmental regulation promotes environmental efficiency, although it presents variations due to the different initial endowments of regional factors. From an input-output perspective, environmental efficiency refers to the impact of effective utilization of factors and value creation on the ecological environment, which is measured by the quantity of expected or unexpected output from inputs per unit factor (Suh \& Huppes, 2005). The goal is to minimize the negative impact on the environment in the process of using elements and promoting value creation (Kaneko \& Managi, 2004). To tackle constant environmental problems and achieve coordination between environmental protection and sustainable economic develop-

${ }^{\star}$ Corresponding author. E-mail: ligx@163.sufe.edu.cn 
ment, China has intensified its efforts in environmental regulation and has increased its investment in the fight against environmental pollution from RMB 493,703 million in 2008 to RMB 921,980 million in $2016^{1}$, thus significantly affecting its economic and environmental performance (Peng et al., 2018). To improve the energy utilization efficiency and China's environmental quality, pollutant emissions should be mitigated, emissions intensity should be reduced, and the enthusiasm of different subjects to participate in environmental pollution treatment should be mobilized (Alford et al., 1997; Jin et al., 2016). However, the various cultural contexts and economic development levels in different regions contribute to different regulation measures and policies, which lead to differences in the impact of environmental regulation on environmental efficiency (Cheng et al., 2017; Hao et al., 2018; Ren et al., 2018). Whether the strengthening of environmental regulation will narrow the regional environmental efficiency gap, enhance the coordination of regional development and affect the convergence of environmental efficiency differences represents an important problem that needs further analysis and discussion.

The literature mainly concentrates on the convergence of carbon emission intensity, energy consumption intensity and energy efficiency (Yang \& Liu, 2012; Churchill et al., 2018; Ivanovski et al., 2018). Scholars have analyzed the factors that affect environmental efficiency, including environmental regulation and technological innovation (Duman \& Kasman, 2018). However, deficiencies are observed in the existing research. First, although scholars have discussed the convergence of regional environmental efficiency, most researchers focused on the convergence of environmental efficiency in a given region while few studies have compared the convergence rate of regional environmental efficiency among different regions. Second, previous research mainly discussed the effect of environmental regulation and the relationship between environmental regulation and environmental efficiency, whereas few scholars have compared the effect of environmental regulation in different regions and determined the reasonable threshold values of environmental regulation. Third, few scholars have analyzed the convergence of regional environmental efficiency differences from the perspective of environmental regulation and systematic analyses have not been performed; the mechanisms and effects of environmental regulation on regional environmental efficiency convergence need to be further explored.

This paper contributes to establishing the following objectives. First, starting from regional differences of environmental efficiency, this paper not only studies the convergence of environmental efficiency differences in a certain region but also analyzes the convergence of environmental efficiency differences between regions and compares the convergence rates of environmental efficiency in different regions. Second, this paper includes environmental regulation in the research framework, analyzes the marginal effect and regional heterogeneity of environmental regulation, establishes a reasonable threshold for environmental regulation for each region to explore whether environmental regulation can promote the convergence of regional environmental efficiency and then narrow the gap of environmental efficiency among the eastern, central and western regions. Third, considering technological innovation activities, such as independent research and development (R\&D) and technology introduc-

\footnotetext{
${ }^{1}$ Data are obtained from the website of the National Bureau of Statistics of China (n.d.).
} 
tion, we explore the mechanisms from the perspectives of R\&D investments, outward foreign direct investment (OFDI) and foreign direct investment (FDI) and analyze whether R\&D investments, OFDI and FDI can help to narrow the regional environmental efficiency gap under the role of environmental regulation to further clarify the relationship between variables.

The Malmquist index method in the DEA (Data Envelopment Analysis) model is used to calculate the regional environmental efficiency in this paper, and the convergence analysis of regional environmental efficiency is based on the $\beta$ absolute convergence model. On this basis, the threshold regression model and fixed effect model are used to explore the effect of environmental regulation on regional environmental efficiency convergence. The main research hypotheses are as follows. First, when the differences in environmental efficiency in China converge, the gap between low and high environmental efficiency areas will gradually narrow and the environmental efficiency of the central and western regions will catch up with that of the eastern regions. Second, environmental regulation can promote the convergence of regional environmental efficiency, when environmental regulation reaches a certain level. Such policies will play a more positive role in the environmental efficiency of low environmental efficiency areas. Third, R\&D investment and OFDI have a significant positive effect on environmental efficiency under environmental regulation and help to narrow the environmental efficiency gap between regions, although a "crowding out effect" may be produced. Next, this paper will discuss the related hypotheses in depth.

Section 1 presents a literature review. Section 2 proposes the theoretical hypotheses. Section 3 describes the research design, including variable selection, model construction, data sources, and descriptive statistics. Section 4 presents the regression results analysis. Finally, the last section provides the conclusions and policy implications.

\section{Literature review}

Scholars have evaluated the economic effects of environmental regulation. Palmer et al. (1995) Gray and Shadbegian (2003) believed that strict environmental regulations will increase the production costs and reduce the competitiveness of enterprises, because R\&D expenditures will increase the direct cost of purchasing end-of-line sewage treatment equipment and upgrading the production mode. Second, to comply with the detailed rules of environmental protection laws and regulations, Rubashkina et al. (2015) thought that investment activities will also be restricted to a certain extent, which will eventually lead to an increase in indirect costs. Greenstone et al. (2012) found that the implementation of the Clean Air Act caused a $4.8 \%$ decline in the total factor productivity (TFP) of US manufacturing. Hering and Poncet (2014) conducted an empirical analysis using the two-control area policy of acid rain and SO2 as a quasi-natural experiment, which was implemented by China in 1998. The results showed that environmental regulations have led to a significant decline in exports from polluting industries. Shi and Xu (2018) came to similar conclusions based on the policy background of China's "11th Five-Year Plan" and indicated that strict environmental regulations reduce the possibility of enterprise exports and further reduce the market value of enterprise exports. Chen et al. (2018b) constructed a triple-difference (DDD) model based 
on time and industry to conduct an empirical analysis, and the research results showed that China's water pollution regulations reduced the output value of industry and pollution from the downstream to the upstream due to different environmental regulation intensities.

However, other scholars hold different views. Porter and Linde (1995) argued that appropriate environmental regulation intensity is conducive to improving enterprises' environmental performance and economic performance. Environmental regulation will lead to corporate innovation and force companies to develop cleaner and lower-cost technologies to reduce pollution and improve resource utilization efficiency. The positive effects can offset the negative impact of additional compliance costs, which is reflected in improved corporate competitiveness and productivity (Wang \& Shen, 2016). Chakraborty and Chatterjee (2017) found that environmental regulations in German have significantly increased the innovation expenditure of Indian dye manufacturing companies (upstream companies).

In addition to evaluating the economic effect of environmental regulation, scholars have analyzed the effect of environmental regulation from the perspective of environmental governance, they suggested that environmental regulation can promote environmental quality to some extent. Auffhammer and Kellogg (2011) used the differences-in-differences and regression discontinuity methods to study whether the implementation of gasoline control policies in the United States can significantly improve air quality, and the results showed that this policy can greatly reduce ozone pollution. Wolff (2014) used the difference in difference method to study the influence of "Low Emission Zone" (LEZ) pollution control policies implemented in Germany on urban air quality, and the results showed that LEZ policies could indeed reduce air pollution. Gehrsitz (2017) then extended the sample period to re-evaluate this policy and reached similar conclusions.

Some scholars measure environmental efficiency from multiple dimensions to further explore the impact of environmental regulation. Miao et al. (2019) calculated and decomposed the TFP of atmospheric environment by using the slack based measure (SBM) efficiency measurement method, analyzed the spatial spillover effect of environmental regulation on TFP. Jin et al. (2019) used the Super-SBM model to calculate the green total factor productivity (GTFP) of industrial water resources under the condition of non-expected output and the GMM model to analyze the impact of environmental regulation on GTFP, and they found that environmental regulation inhibited the improvement of GTFP.

Scholars have also studied the issues relevant to environmental efficiency convergence. Stern (2012) used a stochastic frontier approach to analyze the energy efficiency of 85 countries for 37 years and found that the energy efficiency of these 85 countries has convergence characteristics. Camarero et al. (2013) evaluated the environmental efficiency from 1980 to 2005 in 22 OECD countries and found that environmental efficiency converged among developed economies. Zhang et al. (2015) measured the industrial environmental efficiency of 286 cities at the prefecture level using the super-efficient DEA and showed absolute convergence in industrial environmental efficiency in China. Long et al. (2017) reached the same conclusion from the perspective of the industry. Li et al. (2019) thought that there is convergence in the environmental efficiency in the Beijing-Tianjin-Hebei region, and the inter-regional environmental efficiency is narrowing. Duman and Kasman (2018) also found environmental technical efficiency convergence in European Union. In terms of the industrial pollution con- 
trol efficiency, the effect of environmental pollution control investment in the western region is significant, which has a strong "catch-up effect" to the eastern region ( $\mathrm{Lu} \& \mathrm{Xu}, 2019)^{2}$. From the perspective of energy efficiency, Herrerias (2012) found that the energy efficiency converged to a higher level in developing countries.

\section{Mechanism analysis}

Environmental efficiency shows the input-output efficiency of capital, labor and other factors. The factors will flow across regions because different regions may have different marginal outputs of input factor. The pollution-intensive enterprises in the eastern region gradually moved to the central region, resulting in increased unexpected output of wastewater and gas in the central region (Zhang et al., 2019), and the environmental efficiency is relatively low. However, the economic growth rate of central and western regions has been significantly higher than that of the eastern region in recent years, and the economic scale has continued to expand. Accompanied by the continuous increase of regional R\&D investment (Cao et al., 2019), economic growth will promote technological innovation and management process improvements of enterprises. Meanwhile, China has continuously adjusted its industrial structure, greatly developed high-end equipment manufacturing, and reduced the proportion of the quantity of high polluting industries, such as steel and cement, to achieve green production and green consumption (Sueyoshi \& Yuan, 2017). Relying on the advantages of natural conditions, the central and western regions have developed renewable energy, such as solar and wind energy, improved the environmental efficiency. Energy structure transition have had a positive effect on the central region, where there are more pollution-intensive enterprises, and reduced the energy consumption and unexpected output of enterprises significantly.

Hypothesis 1. Regional environmental efficiency is convergent in the eastern, central and western regions of China. The regions with low environmental efficiency present a "catchup effect" on those with high environmental efficiency.

The impact of environmental regulation on environmental efficiency convergence has significant regional heterogeneity. As an important method of promoting environmental regulation, investments in environmental pollution control strengthen the whole process of environmental pollution control through investments in urban environmental infrastructure, old industrial pollution source control, and "three simultaneous" construction projects. Environmental pollution control investments especially focus on reducing unexpected outputs from the source (Zhang et al., 2020), increasing the utilization efficiency of the per unit input factors, and thereby improving regional environmental efficiency. However, the effect of environmental regulation has obvious regional heterogeneity that is impacted by various factors, such as the pollutant emission intensity, economic development level, and technological innovation capabilities. The central region has more pollution-intensive enterprises than the eastern and western regions, which lead to high levels of pollutant emissions and a low level of environmental efficiency (Tian et al., 2018).

\footnotetext{
${ }^{2}$ Catch-up effect refers to the region with low efficiency catching up with the region with high efficiency.
} 
Enterprises in the central region have a certain path dependence on the extensive mode of production. The emission reduction effect of the central region may be significantly higher than that of the eastern and western regions under the influence of strict environmental regulation policies. But the central region needs a huge scale of environmental pollution control investment because of the scale of pollution. Only when the environmental regulation intensity achieves a certain threshold, the positive effect of environmental regulation will reveal. The threshold may be significantly higher than that in the eastern and western regions. Limited by the initial factors, such as location conditions, the western region lacks the economic foundation and talents for technological innovation (Zhuo \& Deng, 2020), resulting in a higher threshold for environmental regulation compared with that in the eastern region. Both the central and local governments in the western region have always paid considerable attention to enhancing the preservation of ecological environments. While strictly restricting the access of energy-intensive and heavily polluting enterprises, the government has also continuously increased the payments on special transfers used in environmental pollution control and ecological restoration. Therefore, regional environmental efficiency will be promoted rapidly when the environmental regulation reaches a certain threshold in the western region. The eastern region is an economically developed area and has a high level of R\&D investment. Environmental pollution control investments are more effective and targeted. The eastern region has a reasonable industrial structure and a small proportion of pollution-intensive enterprises; therefore, the positive impact of environmental regulation on environmental efficiency will be realized more quickly (Zhu \& Wang, 2013).

Hypothesis 2. Environmental regulation may improve environmental efficiency, and when environmental regulation reaches a certain threshold value, the positive effect on environmental efficiency in the central region is particularly obvious, which will significantly promote the convergence of regional environmental efficiency.

Environmental regulation has an impact on regional innovation behavior and then affects environmental efficiency. First, with the improvement of environmental regulation, to reduce the long-term operating costs and improve product competitiveness, production enterprises, especially pollution-intensive enterprises, will increase R\&D investments, strengthen innovation capabilities and key technology breakthroughs, and promote themselves to move forward to the high end of the value chain. The enterprises further increase the factor utilization efficiency, reduce unexpected outputs in the production process, and promote the convergence of regional environmental efficiency. Second, enterprises have the opportunity to learn advanced foreign production technology and management experience in the process of OFDI, enhance the technological innovation capabilities of OFDI enterprises, and optimize the industrial structure by improving the integration of internal factors, feedback of technological achievements and cross-border flow of talents. The spillover effects of reverse technology are significantly enhanced. OFDI will improve the input-output efficiency of production factors, reduce pollutant emissions, and significantly promote regional environmental efficiency. Finally, increasing the intensity of environmental regulation may result in the loss of FDI, which transfers to areas with relatively low environmental regulation to expand investment profits. The crowding out effect reduces the support of FDI for technological innovation and may reduce regional environmental efficiency to a certain extent. 
Hypothesis 3. Environmental regulation improves regional environmental efficiency by affecting $R \& D$ investments and outward foreign direct investments, although the crowding out effect on foreign direct investments needs attention.

\section{Data and model}

\subsection{Variables}

(1) Explained variables. The explained variable in this paper is the environmental efficiency (eff). Labor, capital and energy resources are input factors, expected output and unexpected output are output indicators, and they are used to measure regional environmental efficiency under the condition of maximizing economic output and minimizing environmental impact. The method of selecting the environmental efficiency evaluation index refers to the work of $\mathrm{Li}$ and $\mathrm{Hu}$ (2012), and Zhang et al. (2014), and we select the following five variables as the input indicators: employment, capital stock, energy consumption standard quantity, water consumption and construction land area. The following four variables as the output indicators: industrial waste gas emission, solid waste emission, industrial waste water emission and gross domestic product (GDP). Refered on the calculation method of Zhang et al. (2004), this paper uses the perpetual inventory method to estimate the capital stock of each region.

$$
K_{i j}=K_{i(j-1)}\left(1-\delta_{i j}\right)+I_{i j} / P_{i j},
$$

where $K$ is the actual capital stock, $P$ is the price indices of investment in fixed assets, $I$ is the amount of fixed asset investment, $\delta$ is the depreciation rate (value of 5\%) (Wang \& Yao, 2001), $i$ is the time dimension, and $j$ is the regional latitude. Choosing the right base period is the key link of the perpetual inventory method, an earlier base period corresponds to a smaller estimation error. This research uses the capital stock data (current year price) in 2000 calculated by Zhang et al. (2004) with the base period in 1952 to estimate the capital stock in China.

The DEA method can be used to perform a scientific assessment of the input-output efficiency. The traditional DEA analysis method indicates that a smaller input leads to a better output. That is, in terms of environmental efficiency, the minimum input is used to obtain the maximum efficiency (Song et al., 2012). The DEA model generally includes two situations: when the input is fixed, the output is the largest; and when the output is fixed, the input is the smallest. These situations emphasize the minimization of input and the maximization of output; the higher the evaluation index, the higher the efficiency. The output indicators are not meet the requirement of the traditional DEA model to maximize output. In this paper, the Malmquist index method in DEA model is used, and in the case of variable returns to scale, environmental efficiency is measured from the perspective of input.

The calculation results show that Beijing, Hainan and Shanghai had the highest environmental efficiency, while Chongqing, Qinghai and Shanxi had the lowest environmental efficiency. From the average of regional environmental efficiency over the study period, the regional environmental efficiency in the developed areas is higher than that in the developing areas, that is, the environmental efficiency of the eastern region is generally higher than 
that of the central and western regions in China. The mean value of environmental efficiency in the central region is the lowest, which is mainly because economically developed regions have made large investments in R\&D. The data in the 2017 China Statistical Yearbook (National Bureau of Statistics of China, 2017) show that the ratio of R\&D spending to the GDP of Beijing reached 5.94 and reached the level of RMB 100 billion. Such intensity has significantly improved the level of technological innovation and played a positive role in improving the efficiency of production factors. Central and local governments have always attached great importance to the protection of ecological features in the western region; therefore, the entry of high pollution enterprises is strictly restricted and the special transfer payment for finance is strengthened, and the environmental efficiency is relatively high. In the central region, due to the high proportion of pollution-intensive enterprises and the limited investment scale of environmental pollution control, the environmental efficiency is relatively low.

Figure 1 shows the environmental efficiency in China from 2008 to 2017. It can intuitively reveal the change trend of environmental efficiency. The $\mathrm{X}$ axis is time, and the $\mathrm{Y}$ axis is environmental efficiency. It can be seen from Figure 1 that except for 2008 and 2015, the environmental efficiency values in other years are greater than 1 . The results show that the environmental efficiency is on the rise in recent years and the efficiency of production factor utilization is constantly improving.

(2) Explanatory variable. The explanatory variable is environmental regulation ( $\mathrm{erl}$ ). This paper describes environmental regulation by environmental pollution treatment investment, which is a market-motivated environmental regulation tool. The greater the environmental pollution treatment investment, the stricter the environmental regulation. Referencing the index selection method of Fredriksson and Millimet (2002), Cole and Elliott (2003), Zhang et al. (2020), based on the investment scale of environmental pollution control, the heterogeneity of regional economic scale is considered. The intensity of environmental regulation is used to describe the situation of regional environmental regulation, it is a relative indicator and signifies the ratio of the environmental pollution treatment investment to the GDP. The higher the ratio, the higher the intensity of the environmental regulation.

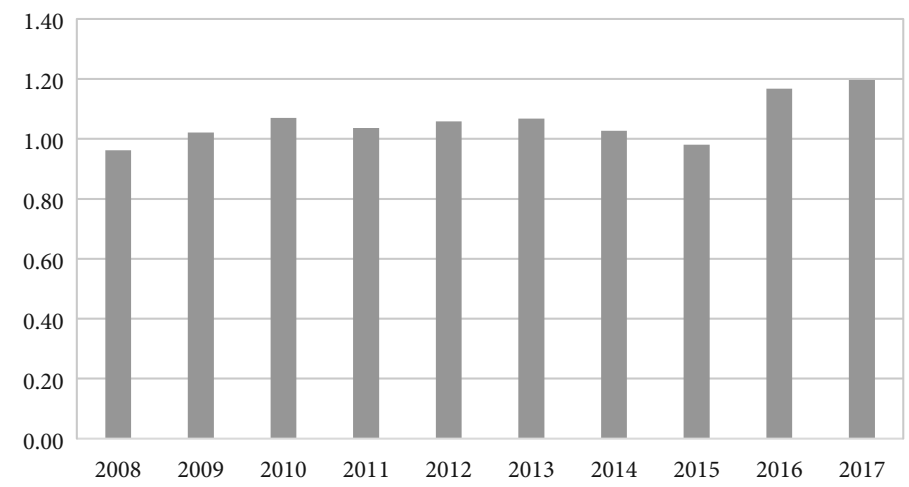

Figure 1. Environmental efficiency in China from 2008 to 2017 (source: National Bureau of Statistics of China, n.d.) 
The scale of environmental pollution control investment is closely related to the scale of regional economy, and areas with a large economic scale often have high total investments in environmental pollution control; however, the environmental pollution control investments per unit pollutants in such region are not necessarily relatively high. This index can effectively eliminate the heterogeneity of industrial scale and economic development between regions.

According to extant research (Maximilian \& Kellogg, 2011; Zhang et al., 2020), this paper has selected the following factors as the control variables of this model. First, the economic development level $(p g d p)$ of a region is a key factor affecting environmental efficiency and spatial convergence and is measured by the ratio of the gross regional domestic product to the resident population. Second, the R\&D investment $(r d)$ is the amount of R\&D investment by industrial enterprises above the designated size. Because technological innovation demands considerable inputs in R\&D, R\&D will promote technological innovation and regional environmental efficiency. Third, industrial structure (tia) is measured by the ratio of the added value of the tertiary industry to GDP. A rising ratio indicates that the industrial structure is becoming increasingly reasonable. Fourth, control variables also include foreign direct investment (fdi), fiscal revenue ( $g r$ ), outward foreign direct investment (ofdi) and resident income ( $r i)$. FDI, OFDI and fiscal revenue are represented by the amount of RMB actually incurred in the current year, and resident income is measured by the per capita disposable income of urban residents.

Using panel data from 30 provincial administrative regions (except Tibet, Hong Kong, Macao and Taiwan) in China for 2008-2017, the problem of regional environmental efficiency convergence and the relationship between environmental regulation and regional environmental efficiency are analyzed. The data of environmental pollution treatment investment come from the China Environmental Statistics Yearbook (2009-2018). R\&D input data come from the China Science and Technology Statistical Yearbook (2009-2018). The primary energy data, such as coal, oil and natural gas, which are involved in the calculation of environmental efficiency, are derived from the China Energy Statistics Yearbook (2009-2018). Emissions of industrial waste gas, solid waste and industrial waste water come from China Energy Statistics Yearbook. Employees, fixed assets depreciation, water consumption, construction land area, residents' income, fiscal revenue, FDI, industrial output value and population are derived from the China Statistical Yearbook.

\subsection{Descriptive statistics}

Before the results of regression analysis are discussed, this paper first analyses the statistical features of the variables in Table 1 . The standard deviation of each variable is relatively small, and the mean value of variables is larger than the standard deviation. The sequence of variables is stable. 
Table 1. Descriptive Statistics of the Variables (source: The data in the table are calculated by the software of STATA)

\begin{tabular}{|l|c|c|c|c|c|}
\hline \multicolumn{1}{|c|}{ Variables } & Mean & Std. Dev. & Min & Max & Obs \\
\hline eff & 1.059 & 0.144 & 0.720 & 1.653 & 300 \\
\hline $\ln e r l$ & 0.014 & 0.007 & 0.004 & 0.042 & 300 \\
\hline $\ln r d$ & 6.055 & 0.604 & 3.943 & 7.271 & 300 \\
\hline $\ln p g d p$ & 4.591 & 0.222 & 3.996 & 5.111 & 300 \\
\hline tia & 0.435 & 0.093 & 0.283 & 0.806 & 300 \\
\hline $\ln f d i$ & 2.208 & 0.599 & -0.678 & 3.395 & 300 \\
\hline $\ln g r$ & 3.030 & 0.410 & 1.747 & 3.948 & 300 \\
\hline $\ln r i$ & 4.360 & 0.155 & 4.040 & 4.796 & 300 \\
\hline $\ln$ ofdi & 1.666 & 0.820 & -1.760 & 3.379 & 300 \\
\hline
\end{tabular}

\subsection{Model construction}

First, assuming the same condition of the structure of initial factors, we refer to the model building method of Zhang et al. (2015) and build the $\beta$ absolute convergence model:

$$
\ln \left(\frac{e f f_{i, j+1}}{e f f_{i, j}}\right)=\alpha_{0}+\beta_{i} \ln e f f_{i, j}+\eta_{i, j},
$$

where $e f f f_{i, j+1}$ and $e f f_{i, j}$ represent the environmental efficiency value of the $j$-th and the $j+$ 1 th years in the ith region; $\alpha_{0}$ is the intercept term; $\eta$ is the error term; $\beta$ is the regression coefficient; and $\beta=-\left(1-e^{-a J}\right) / J$, with $J$ as the time span and $a$ as the convergence speed. When $\beta<0$, the increased speed of environmental efficiency is inversely proportional to the initial level. At this time, there is absolute convergence in environmental efficiency.

When considering the impact of the typical indicators of regional economic and social development, the following $\beta$ conditional convergence model can be built:

$$
\ln \left(\frac{e f f_{i, j+1}}{e f f_{i, j}}\right)=\alpha_{0}+\beta_{i} \ln e f f_{i, j}+\lambda_{k} \operatorname{control}_{k, i, j}+\eta_{i, j},
$$

where control represents the control variables, including economic development level ( $p g d p)$, R\&D investment $(r d)$, industrial structure $(t i a)$, foreign direct investment $(f d i)$, fiscal revenue $(\mathrm{gr})$, and resident income ( $r i)$, outward foreign direct investment (ofdi). $\lambda$ is the regression coefficient of control variable. If the control variables are added, the spatial heterogeneity of environmental efficiency gradually shrinks over time. In other words, when $\beta$ is smaller than 0 , there is $\beta$ conditional convergence in the environmental efficiency.

Second, after the environmental regulation variables are added, the convergence of regional environmental efficiency is further analyzed (including intraregional convergence and convergence differences in different regions). The convergence of regional environmental efficiency may be significantly different at different levels of environmental regulation, there may be a nonlinear relationship between variables. The panel threshold regression model is 
a nonlinear economic model that can more accurately estimate the parameters of different threshold intervals and determine the threshold value (Yang et al., 2019), including single, double, triple thresholds and so on. To further analyze the influence of environmental regulation on the convergence of regional environmental efficiency, the following model is built:

$$
\begin{aligned}
& \ln \left(\frac{\text { eff }_{i, j+1}}{e f f_{i, j}}\right)=\alpha_{0}+\beta_{1} \ln e f f_{i j} I\left(\ln e r l_{i j}<\gamma_{1}\right)+\beta_{2} \ln \operatorname{eff}_{i j} I\left(\gamma_{1} \leq \ln e r l_{i j}<\gamma_{2}\right)+\ldots+ \\
& \beta_{q} \ln e r l_{i j} I\left(\ln e r l_{i j} \geq \gamma_{q}\right)+\lambda_{k} \operatorname{control}_{k, i, j}+\eta_{i, j},
\end{aligned}
$$

where $\gamma$ represents threshold value and $q$ represents threshold quantity.

Third, after comparing the convergence of environmental efficiency in different regions, we further analyses the region heterogeneity of the impact of environmental regulation. Given that most of the current research findings suggest that there is a nonlinear relationship between environmental regulation and environmental efficiency (Pan et al., 2019; Wang \& Shao, 2019), the core explanatory variable is mostly introduced into the model in the form of a quadratic term, and the following nonlinear model is built:

$$
\ln e f f_{i j}=\alpha_{0}+\alpha_{1} \ln e r l_{i j}+\alpha_{2} \ln e r l_{i j}^{2}+\lambda_{k} \operatorname{control}_{k, i, j}+\eta_{i, j},
$$

where $\alpha_{1}$ and $\alpha_{2}$ are the regression coefficient.

Finally, this paper analyses the mechanism of environmental regulation affecting regional environmental efficiency. From the three aspects of R\&D investment, OFDI and FDI, the interaction items of environmental regulation and these three variables are added. itat $_{i j}$ represents the interaction items, including $\ln e r l_{i j} \cdot \ln r d_{i j}, \ln e r l_{i j} \cdot \ln o f d i_{i j}$, and $\ln e r l_{i j} \cdot \ln f d i_{i j}$. The following model is built:

$$
\ln e f f_{i j}=\alpha_{0}+\alpha_{1} i_{t a t} t_{i j}+\lambda_{k} \operatorname{control}_{k, i, j}+\eta_{i, j} .
$$

\section{Empirical analysis}

\subsection{Environmental efficiency convergence analysis}

To study the divergence and convergence of environmental efficiency in different regions during the study period, this paper introduced a spatial convergence analysis method. We can assume that the structures of initial factors, such as the income level, the fiscal capacity, the economic development and the technology level of various administrative regions in a certain region, remain the same over time. Thus, the environmental efficiency will be converged to the same level; namely, it meets $\beta$ absolute convergence. In addition, the model has passed the Chow test, and there is comparability between the groups.

Table 2 shows that there is a convergence trend in the differences of environmental efficiency. The convergence of the difference of environmental efficiency between the central and western regions is significantly higher than that of the eastern region. The convergence of the western region is the strongest, and the absolute value of the regression coefficient is 1.015 , which significantly larger than that of the eastern and central regions. $R^{2}$ is 0.502 . The property of the absolute convergence coefficient shows that when the regression coefficient 
Table 2. Regression result of absolute convergence of environmental efficiency (source: The data in the table are calculated by the software of STATA)

\begin{tabular}{|l|c|c|c|c|}
\hline \multicolumn{1}{|c|}{ Variable } & China & Eastern Region & Central Region & Western Region \\
\hline \multirow{2}{*}{$\ln$ eff } & $-0.687^{* * *}$ & $-0.537^{\star * *}$ & $-0.544^{* * *}$ & $-1.015^{* * *}$ \\
& $(0.061)$ & $(0.094)$ & $(0.119)$ & $(0.102)$ \\
\hline \multirow{2}{*}{ constant } & $0.025^{* * \star}$ & $0.033^{\star * *}$ & $0.023^{* * *}$ & $0.013^{* * \star}$ \\
& $(0.003)$ & $(0.007)$ & $(0.006)$ & $(0.005)$ \\
\hline$R^{2}$ & 0.323 & 0.249 & 0.228 & 0.502 \\
\hline$F$ value & 128.150 & 32.540 & 20.96 & 98.740 \\
\hline
\end{tabular}

Note: “***”, "***" and "*»" represent the significance levels of $1 \%, 5 \%$ and $10 \%$, respectively. The standard error is in ( ). The same notations apply in the following tables.

is negative, the improvement speed of regional environmental efficiency is inversely proportional to the initial level. Therefore, the lower the initial level, the faster the environmental efficiency in the region will be improved. This is consistent with the research conclusion of Zhang et al. (2015), Long et al. (2017). The initial level of environmental efficiency in the central region is the lowest, which shows a stronger "catch-up effect" and higher growth rate compared with the eastern region. This phenomenon is closely related to the industrial structure (i.e., the pollution-intensive enterprises account for a large ratio), economic development level and governmental environmental regulation and policies (Zhang et al., 2019). The "catch-up effect" of environmental efficiency in the western region is the strongest, and the convergence rate of environmental efficiency is significantly higher than that in the eastern and central regions, which may be because the western region is an area with fragile ecological environment and the central and local governments have always attached great importance to the pollutant emissions management and environmental pollution control, thereby providing considerable policy and financial support. Therefore, environmental efficiency shows a faster growth rate and gradually reduces the gap with high environmental efficiency areas.

However, in terms of actual economic and social development, the endowment of initial factors and the structures of the factors of various regions differ greatly. Different regions are significantly different in terms of population scale, economic development level, technology level, fiscal situation and other characteristics, and different regions with the same features may eventually converge to different levels. Therefore, over time, the environmental efficiency of different regions will converge to steady levels, which meets the $\beta$ conditional convergence features.

In Table 3, conditional convergence occurs in the environmental efficiency of China and the three regions after adding the control variables. At the national level, the convergence coefficient is significantly negative and shows that the environmental efficiency tends to converge. The central and western regions have a strong "catch-up effect", and their environmental efficiency improved more quickly, showing that regions with low environmental efficiency will narrow the gap with regions with high environmental efficiency. This is basically consistent with the research conclusion of Yu et al. (2018), and also accepts hypothesis 1 . The convergence of environmental efficiency in the central and western regions is significantly higher than the national average, with the lowest in the eastern region and the 
Table 3. Regression result of conditional convergence of environmental efficiency (source: The data in the table are calculated by the software of STATA)

\begin{tabular}{|c|c|c|c|c|}
\hline Variable & China & Eastern Region & Central Region & Western Region \\
\hline $\ln e f f$ & $\begin{array}{c}-0.781^{\star * *} \\
(0.059)\end{array}$ & $\begin{array}{c}-0.753^{\star * \star} \\
(0.101)\end{array}$ & $\begin{array}{c}-0.870^{\star \star \star} \\
(0.123)\end{array}$ & $\begin{array}{c}-1.029^{\star * \star} \\
(0.097)\end{array}$ \\
\hline $\ln r i$ & $\begin{array}{l}0.226^{*} \\
(0.116)\end{array}$ & $\begin{array}{c}0.162 \\
(0.181)\end{array}$ & $\begin{array}{c}0.211 \\
(0.352)\end{array}$ & $\begin{array}{l}0.430^{* *} \\
(0.183)\end{array}$ \\
\hline $\ln g r$ & $\begin{array}{l}-0.089^{\star} \\
(0.045)\end{array}$ & $\begin{array}{l}-0.046 \\
(0.074)\end{array}$ & $\begin{array}{c}0.017 \\
(0.082)\end{array}$ & $\begin{array}{l}-0.143 \\
(0.110)\end{array}$ \\
\hline tia & $\begin{array}{l}0.205^{\star *} \\
(0.104)\end{array}$ & $\begin{array}{l}0.266^{*} \\
(0.158)\end{array}$ & $\begin{array}{l}0.552^{*} \\
(0.281)\end{array}$ & $\begin{array}{l}-0.243 \\
(0.202)\end{array}$ \\
\hline $\ln p g d p$ & $\begin{array}{l}-0.028 \\
(0.102)\end{array}$ & $\begin{array}{l}0.371^{\star *} \\
(0.180)\end{array}$ & $\begin{array}{l}-0.058 \\
(0.273)\end{array}$ & $\begin{array}{l}-0.229 \\
(0.172)\end{array}$ \\
\hline $\ln r d$ & $\begin{array}{l}0.011^{\star} \\
(0.006)\end{array}$ & $\begin{array}{l}0.195^{\star *} \\
(0.085)\end{array}$ & $\begin{array}{c}0.153 \\
(0.117)\end{array}$ & $\begin{array}{c}0.044 \\
(0.090)\end{array}$ \\
\hline $\ln f d i$ & $\begin{array}{l}0.006^{\star} \\
(0.003)\end{array}$ & $\begin{array}{l}0.049^{\star} \\
(0.027)\end{array}$ & $\begin{array}{l}0.023^{\star *} \\
(0.012)\end{array}$ & $\begin{array}{l}-0.004 \\
(0.021)\end{array}$ \\
\hline $\ln o f d i$ & $\begin{array}{l}0.089^{*} \\
(0.051)\end{array}$ & $\begin{array}{c}0.126^{* * *} \\
(0.042)\end{array}$ & $\begin{array}{l}0.078^{\star} \\
(0.039)\end{array}$ & $\begin{array}{c}0.065 \\
(0.055)\end{array}$ \\
\hline constant & $\begin{array}{c}-0.631^{* *} \\
(0.243)\end{array}$ & $\begin{array}{c}-1.340^{* * *} \\
(0.441)\end{array}$ & $\begin{array}{c}-0.509^{\star * *} \\
(0.211)\end{array}$ & $\begin{array}{c}-0.573^{\star *} \\
(0.278)\end{array}$ \\
\hline$R^{2}$ & 0.439 & 0.451 & 0.394 & 0.552 \\
\hline$F$ value & 27.092 & 11.273 & 5.902 & 16.814 \\
\hline
\end{tabular}

highest in the central region. In terms of the influence of control variables, resident income $(\ln r i)$, FDI $(\ln f d i), \mathrm{R} \& D(\ln r d)$, industrial structure $(t i a)$, OFDI (lnofdi)have positive effects on the convergence of regional environmental efficiency. Fiscal revenue (lngr) and economic development $(\ln p g d p)$ restrain the convergence of regional environmental efficiency to a certain extent, which is mainly because the regions with high fiscal revenue and economic development have stronger comprehensive strength, the scale of environmental pollution control investment is generally high, pollution control measures are relatively optimal, and the emission of pollutants produced per unit factor input is low. Good regional development conditions make the regional environmental efficiency improve rapidly, thereby further widening the gap with other regions.

\subsection{Environmental regulation and environmental efficiency}

We refer to the treatment method of Bai and Liu (2020), based on the conditional convergence model, the variable of environmental regulation is added and the threshold regression model is used to analyze the effect of environmental regulation.

In Table 4, the double threshold effect of environmental regulation on regional environmental efficiency convergence is significant in China, with the single threshold of 0.010 and the double threshold of 0.016 . The single threshold effect of environmental regulation is significant in the eastern, central and western regions, and the threshold values are 0.011, 0.015 and 0.012 , respectively. 
Table 4. Results of the threshold effect test (source: The data in the table are calculated by the software of STATA)

\begin{tabular}{|c|c|c|c|c|}
\hline Threshold Quantity & China & Eastern Region & Central Region & Western Region \\
\hline Single threshold & $\begin{array}{c}0.010^{* * *} \\
(0.010)\end{array}$ & $\begin{array}{l}0.011^{*} \\
(0.063)\end{array}$ & $\begin{array}{c}0.015^{* * *} \\
(0.003)\end{array}$ & $\begin{array}{l}0.012^{*} \\
(0.098)\end{array}$ \\
\hline Double threshold & $\begin{array}{l}0.016^{*} \\
(0.073)\end{array}$ & $\begin{array}{c}0.012 \\
(0.670)\end{array}$ & $\begin{array}{c}0.016 \\
(0.307)\end{array}$ & $\begin{array}{c}0.014 \\
(0.183)\end{array}$ \\
\hline Triple threshold & $\begin{array}{c}0.015 \\
(0.653)\end{array}$ & - & - & - \\
\hline
\end{tabular}

Table 5 shows that the convergence rate of regional environmental efficiency is different at different threshold interval. In different threshold areas, the convergence rate of environmental efficiency in the central and western regions is significantly higher than that in the eastern region. Especially in the central region, when the level of environmental regulation is greater than 0.015 , the convergence rate of regional environmental efficiency is significantly improved and more than 2 times that of the eastern and western regions. In addition, the regression coefficient is -2.797 , which is significant at the level of $1 \%$. At the national level, when the environmental regulation intensity is between 0.010 and 0.016 , the convergence of regional environmental efficiency is the strongest and the impact coefficient is -1.043 , which is significant at the level of $1 \%$. Therefore, there is a significant negative correlation between the initial level of regional environmental efficiency and its improvement speed under the influence of environmental regulation. The lower the initial level of environmental efficiency, the stronger the effect of environmental regulation. For the central and western regions with low environmental efficiency, environmental regulation makes them catch up with the eastern region with a higher growth rate of environmental efficiency, thereby narrowing the gap of environmental efficiency between regions and reaching a higher level. The implication accepts the hypothesis 2 .

Table 5. Threshold regression results (source: The data in the table are calculated by the software of STATA)

\begin{tabular}{|c|c|c|c|c|c|}
\hline Variable & China & Variable & $\begin{array}{l}\text { Eastern } \\
\text { Region }\end{array}$ & $\begin{array}{l}\text { Central } \\
\text { Region }\end{array}$ & $\begin{array}{l}\text { Western } \\
\text { Region }\end{array}$ \\
\hline $\ln e f f I\left(\ln e r l<\gamma_{1}\right)$ & $\begin{array}{c}-0.501^{\star * *} \\
(0.101)\end{array}$ & $\ln e f f I\left(\ln e r l<\gamma_{1}\right)$ & $\begin{array}{c}-0.574^{* * *} \\
(0.156)\end{array}$ & $\begin{array}{c}-0.743^{\star * \star} \\
(0.139)\end{array}$ & $\begin{array}{c}-0.667^{* * *} \\
(0.172)\end{array}$ \\
\hline $\ln e f f I\left(\gamma_{1} \leq \ln e r l<\gamma_{2}\right)$ & $\begin{array}{c}-1.043^{* * *} \\
(0.083)\end{array}$ & $\ln e f f I\left(\ln e r l \geq \gamma_{1}\right)$ & $\begin{array}{c}-0.998^{* * *} \\
(0.119)\end{array}$ & $\begin{array}{c}-2.797^{\star * *} \\
(0.593)\end{array}$ & $\begin{array}{c}-1.223^{* * *} \\
(0.122)\end{array}$ \\
\hline $\ln e f f I\left(\ln e r l \geq \gamma_{2}\right)$ & $\begin{array}{c}-0.672^{* * *} \\
(0.113)\end{array}$ & - & - & - & - \\
\hline control variables & Yes & Control variables & Yes & Yes & Yes \\
\hline constant & $\begin{array}{c}-0.587^{* *} \\
(0.229)\end{array}$ & Constant & $\begin{array}{c}-1.361^{* * *} \\
(0.436)\end{array}$ & $\begin{array}{c}0.167 \\
(0.482)\end{array}$ & $\begin{array}{l}-0.385 \\
(0.465)\end{array}$ \\
\hline$F$ value & 20.841 & $F$ value & 8.830 & 16.120 & 13.550 \\
\hline$R^{2}$ & 0.445 & $R^{2}$ & 0.469 & 0.497 & 0.575 \\
\hline
\end{tabular}


To further analyze the regional heterogeneity of the impact of environmental regulation on regional environmental efficiency and provide a better understanding of the reaction relation between the variables, this paper introduces a nonlinear model using the quadratic term, further verifies whether environmental regulation will have a greater positive impact on regions with stronger convergence in environmental efficiency. If the answer is Yes, then low environmental efficiency areas will catch up with high environmental efficiency areas at a higher speed under the influence of environmental regulations.

Table 6 shows that environmental regulation has the effect of first restraining and then promoting regional environmental efficiency. In the eastern, central and western regions, environmental regulation has similar effects on regional environmental efficiency, although the inflection of each region is different. In the process of affecting regional environmental efficiency, the inflection point value of environmental regulation in the central region is larger, which is 0.025 . Next is the western region, which has an inflection point value of environmental regulation of 0.023 . The inflection point value of environmental regulation in the eastern region is the lowest at 0.011 . The results show that the central region needs to strengthen environmental regulation to solve environmental problems and improve regional environmental efficiency. The main reasons are as follows. First, environmental regulation policies in the eastern region have become increasingly strict in recent years; thus, pollutionintensive enterprises have gradually shifted from the eastern region to the central region so as to reduce production costs. As a result, the emission intensity of pollutants in the central region is high and the distribution of polluting enterprises is relatively intensive (Zhang et al., 2019). Enterprises present path dependence on high consumption and high pollution production modes in the central region, the regional environmental efficiency should be improved with higher environmental regulation intensity (Piao et al., 2019). Second, increasing level of environmental decentralization, the environmental powers of local governments are expanding gradually. However, the resources of environmental administration, environmental monitoring and environmental supervision in the central region cannot effectively match the huge pollution sources. These institutional defects reduce the effectiveness and pertinence of environmental regulation and then affect the pollution control efficiency.

Table 6. Regression results of the impact of environmental regulation on environmental efficiency (source: The data in the table are calculated by the software of STATA)

\begin{tabular}{|l|c|c|c|}
\hline \multicolumn{1}{|c|}{ Variable } & Eastern Region & Central Region & Western Region \\
\hline \multirow{2}{*}{$\ln$ erl } & -0.005 & $-0.068^{\star}$ & $-0.121^{\star * *}$ \\
& $(0.020)$ & $(0.040)$ & $(0.032)$ \\
\hline \multirow{2}{*}{$\ln ^{2}{ }^{2}$} & 0.228 & $1.383^{\star}$ & $2.589^{\star * *}$ \\
& $(0.406)$ & $(0.791)$ & $(0.775)$ \\
\hline control variables & Yes & Yes & Yes \\
\hline \multirow{2}{*}{ constant } & $0.928^{* * *}$ & 0.475 & $\left(.228^{\star *}\right.$ \\
& $(0.365)$ & $(0.669)$ & $0.609)$ \\
\hline$R^{2}$ & 0.655 & 0.621 & 233.200 \\
\hline$F$ value & 47.310 & 115.880 & \\
\hline
\end{tabular}


The inflection point value of environmental regulation in the western region is slightly lower than that in the central region, while the inflection point value of environmental regulation in the eastern region is the lowest. The reason is that economic development and technological innovation ability of enterprises is relatively low in the western region, only when environmental regulation exceeds the inflection point, capital accumulation will promote technological innovation. The eastern region has a huge economic scale and R\&D investment scale; thus, technological innovation has formed a good path dependence. The strict environmental regulation policies in the eastern region have gradually reduced the number of pollution-intensive enterprises and made the industrial structure more and more advanced. The input-output efficiency of factors has been greatly improved, and the pertinence and effectiveness of environmental pollution control investment have been gradually improved. Therefore, environmental regulation in the eastern region is more likely to play a positive role in environmental efficiency.

\subsection{Further discussion}

How does environmental regulation affect regional environmental efficiency? Technological innovation is the core driving force to improve the competitiveness of enterprises, optimize the industrial structure and improve environmental efficiency (Porter, 1991; Guo et al. 2017; Miao et al. 2018). Technological innovation mainly comes from independent R\&D and technology introduction (Chen et al. 2018a). The level of regional independent R\&D mainly depends on the scale of the region's $\mathrm{R} \& \mathrm{D}$ investment, and there is a positive correlation between them. Moreover, the multinational enterprises are the main carriers of technology introduction. Foreign multinational enterprises bring advanced production technology to Chinese enterprises through investment, thereby optimizing the production process. China's multinational enterprises strengthen the spillover effect of reverse technology through crossborder merger and acquisition and green investment. This paper will analyze the mechanism of environmental regulation from three aspects: R\&D investment, OFDI and FDI.

First, R\&D investment. To further study whether environmental regulation can reduce environmental pollution and improve environmental efficiency by increasing R\&D investment, an interaction term $(\ln e r l \cdot \ln r d)$ between environmental regulation and R\&D investment is introduced.

Table 7 shows that environmental regulation can improve regional environmental efficiency by increasing R\&D investment. The regression results of the eastern, central, and western regions show that the interaction term of environmental regulation and R\&D investment have a positive effect on regional environmental efficiency, although this effect has obvious regional differences. The regression coefficient in the central region is the largest at 0.301 and significant at the level of $10 \%$, and it is followed by that of the western region at 0.143 . The interaction term of environmental regulation and $R \& D$ investment has the least impact on regional environmental efficiency in the eastern region, which is only 0.002 and not significant. It can be seen that environmental regulation will significantly increase R\&D investment in the central and western regions, promote regional environmental efficiency faster. The implication accepts the hypothesis 3. 
Table 7. Effect of R\&D investment (source: The data in the table are calculated by the software of STATA)

\begin{tabular}{|l|c|c|c|}
\hline \multicolumn{1}{|c|}{ Variable } & Eastern region & Central region & Western region \\
\hline lnerl. $\ln r d$ & 0.002 & $0.301^{\star}$ & $0.143^{\star}$ \\
& $(0.046)$ & $(0.171)$ & $(0.081)$ \\
\hline control variables & Yes & Yes & Yes \\
\hline \multirow{2}{*}{ constant } & $-1.785^{*}$ & 2.380 & $-1.867^{\star}$ \\
& $(0.923)$ & $(2.635)$ & $(1.128)$ \\
\hline$F$ value & 48.46 & 37.54 & 16.85 \\
\hline$R^{2}$ & 0.325 & 0.346 & 0.158 \\
\hline
\end{tabular}

The reason for these findings is that the pollution-intensive enterprises in the eastern region are gradually transferred to the central region, resulting in a large proportion of highly polluting enterprises in the central region and a high level of pollutant emissions. With the improvement of environmental regulation, enterprises have responded more strongly in the central region, which is mainly because the environmental pollution control investment needs the corresponding support of capital investments by enterprises. Improving environmental regulation will significantly increase the production cost of enterprises in the central region, inhibit economic output, and affect the production and business activities of enterprises. To reduce long-term operating costs, enterprises will continue to expand the scale of R\&D to improve technological innovation capabilities, reduce undesired output in the production process, and thereby improve environmental efficiency and core competitiveness. The strict protection of the ecological environment by the local governments in the western region and the forbidden access mechanism for high polluting enterprises have formed a high-pressure situation of environmental protection, which is helpful for promoting enterprises to increase $\mathrm{R} \& \mathrm{D}$ investment. The stock level of technological innovation and the proportion of clean production enterprises in the eastern region are relatively high and the industrial structure is more reasonable. However, compared with developed regions, the environmental regulation intensity is relatively low (Wang et al., 2019) and thus cannot effectively force the independent innovation of enterprises in the eastern region.

Second, OFDI. In the model (5), the interaction term lnerl-lnofdi is added to analyze how environmental regulation affects environmental efficiency through OFDI. Table 8 shows that the interaction terms of environmental regulation and OFDI have a positive effect on regional environmental efficiency, it is most obvious in the central region. The implication accepts the hypothesis 3 . In central region, the regression coefficient is 0.029 , and it is significant. The regression coefficient in the eastern region is 0.013 , which is significant at the level of $5 \%$. The regression coefficient is not significant in the western region, the value is 0.017. The reason for these findings is that there is an obvious demand for technological innovation in the central region. In the process of OFDI, multinational enterprises pay more attention to the introduction of foreign advanced production technology and the reverse technology spillover effect is particularly obvious. The regression coefficient of lnerl-lnofdi in the western region is not significant, because the economy is relatively backward and the 
Table 8. Effect of outward foreign direct investment (source: The data in the table are calculated by the software of STATA)

\begin{tabular}{|l|c|c|c|}
\hline \multicolumn{1}{|c|}{ Variable } & Eastern region & Central region & Western region \\
\hline \multirow{2}{*}{ lnerl. $\ln$ ofdi } & $0.013^{* *}$ & $0.029^{* * *}$ & 0.017 \\
& $(0.006)$ & $(0.004)$ & $(0.021)$ \\
\hline control variables & Yes & Yes & Yes \\
\hline \multirow{2}{*}{ constant } & $-0.631^{* *}$ & $-0.974^{* * *}$ & -0.224 \\
& $(0.324)$ & $(0.431)$ & $(0.546)$ \\
\hline$F$ value & 52.37 & 32.6 & 8.56 \\
\hline$R^{2}$ & 0.316 & 0.318 & 0.149 \\
\hline
\end{tabular}

number of multinational enterprises is relatively small. Therefore, it is difficult to improve the technological innovation ability of enterprises by means of OFDI under the influence of environmental regulation. Therefore, regulation does not have a significant positive effect on regional environmental efficiency.

Third, FDI. In model (5), the interaction term $\ln e r l^{*} \ln f d i$ is added to analyze how environmental regulation affects environmental efficiency through FDI. Table 9 shows that the interaction terms of environmental regulation and FDI have a negative impact on regional environmental efficiency, although the impact in the central region is not significant. Environmental regulation may reduce regional environmental efficiency by inhibiting FDI. The implication accepts the hypothesis 3 . The regression coefficient of the interaction term between environmental regulation and FDI shows that the negative influence in the eastern region is the largest. The coefficient is -0.066 in the western region, the negative effect was second only to that in the eastern region. The negative influence in the central region is the lowest, and the regression coefficient is not significant because the initial level of environmental regulation in the eastern region is relatively high. Part of FDI will gradually withdraw from the eastern region's market to seek better pollution shelters under the influence of environmental regulation. As a result, the innovation investment and technical support in the eastern region have been reduced to a certain extent and the environmental efficiency has been significantly inhibited. The strict environmental policy in the western region has also caused foreign direct investment enterprises to make similar strategic choices and gradually withdraw from the western region or the Chinese market, which has an inhibition effect on environmental efficiency. The reason why the regression coefficient is not significant in the central region is that the central region may change the direction of environmental regulation due to the demand for economic development, which will reduce environmental regulation for foreign-funded enterprises with high pollution and high output and strengthen environmental constraints on foreign-funded enterprises with low output. While maintaining the improvement of environmental regulation, the demand for economic development can guarantee the rapid development of regional economy. Therefore, environmental regulation may inhibit regional environmental efficiency by influencing FDI, although this effect is not significant. 
Table 9. Effect of foreign direct investment (source: The data in the table are calculated by the software of STATA)

\begin{tabular}{|l|c|c|c|}
\hline \multicolumn{1}{|c|}{ Variable } & Eastern region & Central region & Western region \\
\hline \multirow{2}{*}{ lnerl. $\ln f d i$} & $-0.114^{* *}$ & -0.047 & $-0.066^{* *}$ \\
& $(0.053)$ & $(0.110)$ & $(0.032)$ \\
\hline control variables & Yes & Yes & Yes \\
\hline \multirow{2}{*}{ constant } & $-2.202^{* * *}$ & -0.095 & -0.472 \\
& $(0.531)$ & $(0.666)$ & $(0.518)$ \\
\hline$F$ value & 7.236 & 2.773 & 3.021 \\
\hline$R^{2}$ & 0.389 & 0.257 & 0.161 \\
\hline
\end{tabular}

\section{Conclusions}

This paper studies the regional heterogeneity of environmental efficiency convergence, and explores the impact of environmental regulation on environmental efficiency convergence. The following results were obtained. (1) The DEA-Malmquist index is used to calculate the environmental efficiency, and the results show that the environmental efficiency is the highest in the eastern region followed by the western region, while the central region is the lowest. (2) The differences of environmental efficiency are converging in China, as well as in the eastern, central and western regions. The convergence rate of environmental efficiency differences between the central and western regions is significantly higher than that of the eastern region. The low environmental efficiency areas will catch up with the high environmental efficiency areas. (3) Environmental regulation has the effect of first restraining and then promoting regional environmental efficiency. When environmental regulation passes a certain threshold, the growth rate of environmental efficiency in the central and western regions with low environmental efficiency will be significantly higher than that of the eastern region. (4) R\&D investment and OFDI can significantly improve the regional environmental efficiency under the influence of environmental regulation, at the same time, we should be alert to the crowding out effect on FDI.

Based on the empirical study, we identified the following policy implications.

(1) To break down the institutional obstacles and administrative barriers that impede regional coordinated development, the communication and coordination among the regions should be strengthened and interest- and risk-sharing mechanisms should be built for regional coordinated development. In the central and western regions, the vertical and horizontal fiscal transfer payment mechanisms are improved and environmental pollution treatment investments are enhanced; therefore, enhancing policy support for regions with backward environmental efficiency encourages local governments and enterprises to reduce emissions voluntarily to obtain more preferential policies; strengthen environmental administration, surveillance and supervision; and improve effective and targeted environmental regulation. In addition, the exit of low-efficiency and heavily polluting enterprises from the market should be accelerated, a strict market access mechanism should be established, heavily polluting enterprises should be restricted from transfer- 
ring to the central region and industrial transformation and upgrades as well as energy conservation and emission reduction should be promoted in regions with low environmental efficiency.

(2) To formulate different environmental regulation strategies for different regions. In the context of China's high-quality economic development, the theory that "only GDP matters" should be eliminated in the regions with low environmental efficiency, and regional environmental pollution treatments should be intensified. For regions with low environmental efficiency, efforts in environmental pollution treatment should be improved, more command-and-control environmental regulation policies should be enacted, the development of energy-intensive and high-emission enterprises should be restricted, the excessive concentration of highly polluting industries should be prevented, the industrial layout of the regions should be optimized, the reliance of economic development on energy consumption should be reduced, and the intensity of energy consumption should be gradually lowered. At the same time, to prevent the regions with low environmental efficiency from falling into the "steady-equilibrium" trap of "low environmental efficiency", we will improve the structure of environmental pollution treatment investments, increase the input in the "three simultaneities" of construction projects and the treatment of sources of old industrial pollution, resolve current problems and eliminate root causes by controlling environmental pollution from the source and reducing the emissions of pollutants from per unit production. For the regions with high environmental efficiency, we will mainly rely on the "incentive" environmental regulation tools, stimulate the innovation potential of industrial enterprises.

(3) To increase the spending on R\&D and improve the transformation of achievements of technological innovation, a number of changes should be made. In the central region, industrial enterprises-especially polluting enterprises-account for a large proportion, although their R\&D input is far less than that in the central region. Thus, we will inject more investment in $\mathrm{R} \& \mathrm{D}$ in the central region with low environmental efficiency, increase their percentage of the GDP, enhance the support for the innovation or introduction of technology for polluting enterprises and accelerate technology diffusion in regions with low environmental efficiency. In addition, we will further strengthen the cooperation at the industry-university-research level between industrial enterprises and scientific research institutions and universities (colleges), promote $\mathrm{R} \& \mathrm{D}$ and the application of green production technology in the eastern region and encourage the transformation of technological innovation achievements to continue increasing environmental efficiency with technological innovation.

This paper studies the relationship between environmental regulation and regional environmental efficiency convergence from the provincial-level administrative regions. However, the impact of environmental regulation on regional environmental efficiency convergence has not been further explored from the micro-enterprise level, and an optimal intensity of environmental regulation has not been identified that can maintain the continuous improvement of environmental efficiency. For future research, it will be very meaningful to consider the effect of industry heterogeneity in environmental regulations on the regional environ- 
mental efficiency convergence and formulate environmental regulation strategies. In addition, under the condition of ensuring the normal production and operation of enterprises, each region should determine an optimal range of environmental regulation intensities in the future according to the actual development situation to promote sustainable economic development while improving environmental efficiency.

\section{References}

Alford, W. P., \& Shen, Y. (1997). Limits of the law in addressing China's environmental dilemma. Stanford Environmental Law Journal, 99(1), 49-54.

Auffhammer, M., \& Kellogg, R. (2011). Clearing the Air? The effects of gasoline content regulation on air quality. American Economic Review, 101(6), 2687-2722. https://doi.org/10.1257/aer.101.6.2687

Bai, J., \& Liu, Y. (2020). Is market integration conducive to spatial convergence of regional innovation. Finance \& Trade Economics, (1), 1-14. http://doi.org/10.19795/j.cnki.cn11-1166/f.20200103.008

Camarero, M., Castillo, J., Picazo-Tadeo, A. J., \& Tamarit, C. (2013). Eco-efficiency and convergence in OECD countries. Environmental and Resource Economics, 55(1), 87-106. https://doi.org/10.1007/s10640-012-9616-9

Cao, K., Zhang, W., Liu, S., Huang, B., \& Huang, W. (2019). Pareto law-based regional inequality analysis of PM2.5 air pollution and economic development in China. Journal of Environmental Management, 252(24), 109635. https://doi.org/10.1016/j.jenvman.2019.109635

Chakraborty, P., \& Chatterjee, C. (2017). Does environmental regulation indirectly induce upstream innovation? New evidence from India. Research Policy, 46(5), 939-955.

https://doi.org/10.1016/j.respol.2017.03.004

Chen, C., Lan, Q., Gao, M., \& Sun, Y. (2018a). Green total factor productivity growth and its determinants in China's industrial economy. Sustainability, 10(4), 1052-1078. https://doi.org/10.3390/su10041052

Chen, Z., Kahn, M. E., Liu, Y., \& Wang, Z. (2018b). The consequences of spatially differentiated water pollution regulation in China. Journal of Environmental Economics and Management, 88(3), 468-485. https://doi.org/10.1016/j.jeem.2018.01.010

Cheng, Z., Li, L., \& Liu, J. (2017). The emissions reduction effect and technical progress effect of environmental regulation policy tools. Journal of Cleaner Production, 149(4), 191-205. https://doi.org/10.1016/j.jclepro.2017.02.105

China Environmental Statistics Yearbook. (2009-2018). https://data.cnki.net/yearbook/Single/ N2019030257

China Science and Technology Statistical Yearbook. (2009-2018). https://data.cnki.net/yearbook/Single/ N2020030067

China Energy Statistics Yearbook. (2009-2018). https://data.cnki.net/yearbook/Single/N2019080025

Churchill, S. A., Inekwe, J., \& Ivanovski, K. (2018). Conditional convergence in per capita carbon emissions since 1900. Applied Energy, 228(10), 916-927. https://doi.org/10.1016/j.apenergy.2018.06.132

Cole, M. A., \& Elliott, R. J. R. (2003). Do environmental regulations influence trade patterns? Testing old and new trade theories. The World Economy, 26(8), 1163-1186. https://doi.org/10.1111/1467-9701.00567

Duman, Y. S., \& Kasman, A. (2018). Environmental technical efficiency in EU member and candidate countries: A parametric hyperbolic distance function approach. Energy, 147(3), 297-307. https://doi.org/10.1016/j.energy.2018.01.037 
Fredriksson, P. G., \& Millimet, D. L. (2002). Is there a "California effect" in US environmental policy making. Regional Science and Urban Economics, 32(6), 737-764. https://doi.org/10.1016/S0166-0462(01)00096-5

Gehrsitz, M. (2017). The effect of low emission zones on air pollution and infant health. Journal of Environmental Economics and Management, 83(5), 121-144. https://doi.org/10.1016/j.jeem.2017.02.003

Gray, W. B., \& Shadbegian, R. J. (2003). Plant vintage, technology, and environmental regulation. Journal of Environmental Economics \& Management, 46(3), 384-402. https://doi.org/10.1016/S0095-0696(03)00031-7

Greenstone, M., List, J. A., \& Syverson, C. (2012). The effects of environmental regulation on the competitiveness of U.S. manufacturing. Social Science Electronic Publishing, 93(2), 431-435. https://doi.org/10.3386/w18392

Guo, L., Qu, Y., \& Tseng, M. (2017). The interaction effects of environmental regulation and technological innovation on regional green growth performance. Journal of Cleaner Production, 162(27), 894-902. https://doi.org/10.1016/j.jclepro.2017.05.210

Hao, Y., Deng, Y., Lu, Z., \& Chen, H. (2018). Is environmental regulation effective in China? Evidence from city-level panel data. Journal of Cleaner Production, 188(7), 966-976. https://doi.org/10.1016/j.jclepro.2018.04.003

Hering, L., \& Poncet, S. (2014). Environmental policy and exports: Evidence from Chinese cities. Journal of Environmental Economics and Management, 68(2), 296-318. https://doi.org/10.1016/j.jeem.2014.06.005

Herrerias, M. J. (2012). World energy intensity convergence revisited: A weighted distribution dynamics approach. Energy Policy, 49(10), 383-399. https://doi.org/10.1016/j.enpol.2012.06.044

Jin, W., Zhang, H., Liu, S., \& Zhang, H. (2019). Technological innovation, environmental regulation, and green total factor effciency of industrial water resources. Journal of Cleaner Production, 211(6), 61-69. https://doi.org/10.1016/j.jclepro.2018.11.172

Jin, Y., Andersson, H., \& Zhang, S. (2016). Air pollution control policies in China: A retrospective and prospects. International Journal of Environmental Research \& Public Health, 12(13), 1219. https://doi.org/10.3390/ijerph13121219

Kaneko, S., \& Managi, S. (2004). Environmental productivity in China. Economics Bulletin, 17(2), 1-10.

Li, L., \& Hu, J. (2012). Ecological total-factor energy efficiency of regions in China. Energy Policy, 46(3), 216-224. https://doi.org/10.1016/j.enpol.2012.03.053

Li, N., Zhang, X., Shi, M., \& Hewings, G. (2019). Does China’s air pollution abatement policy matter? An assessment of the Beijing-Tianjin-Hebei region based on a multi-regional CGE model. Energy Policy, 127(4), 213-227. https://doi.org/10.1016/j.enpol.2018.12.019

Long, X., Sun, M., Cheng, F., \& Zhang, J. (2017). Convergence analysis of eco-efficiency of China's cement manufacturers through unit root test of panel data. Energy, 134(9), 709-717. https://doi.org/10.1016/j.energy.2017.05.079

$\mathrm{Lu}, \mathrm{X}$., \& Xu, C. (2019). The difference and convergence of total factor productivity of inter-provincial water resources in China based on three- stage DEA-Malmquist index model. Sustainable Computing: Informatics and Systems, 22(6), 75-83. https://doi.org/10.1016/j.suscom.2019.01.019

Ivanovski, K., Churchill, S. A., \& Smyth, R. (2018). A club convergence analysis of per capita energy consumption across Australian regions and sectors. Energy Economics, 76(11), 519-531. https://doi.org/10.1016/j.eneco.2018.10.035

Maximilian, A., \& Kellogg, R. (2011). Clearing the air? The effects of gasoline content regulation on air quality. American Economic Review, 101(6), 2687-2722. https://doi.org/10.1257/aer.101.6.2687

Miao, C., Fang, D., Sun, L., Luo, Q., \& Yu, Q. (2018). Driving effect of technology innovation on energy utilization efficiency in strategic emerging industries. Journal of Cleaner Production, 170(1), 1177-1184. https://doi.org/10.1016/j.jclepro.2017.09.225 
Miao, Z., Baležentis, T., Tian, Z., Shao, S., Geng, Y., \& Wu, R. (2019). Environmental performance and regulation effect of China's atmospheric pollutant emissions: Evidence from "Three Regions and Ten Urban Agglomerations". Environmental and Resource Economics, 74, 211-242. https://doi.org/10.1007/s10640-018-00315-6

National Bureau of Statistics of China. (n.d.). http://www.stats.gov.cn/tjsj/ndsj/

National Bureau of Statistics of China. (2017). China Statistical Yearbook 2017. http://www.stats.gov. cn/tjsj/ndsj/2017/indexch.htm

Palmer, K., Oates, W. E., \& Portney, P. (1995). Tightening environmental standards: the benefit-cost or the no-cost paradigm. Journal of Economic Perspectives, 9(4), 119-132. https://doi.org/10.1257/jep.9.4.119

Pan, X., Ai, B., Li, C., Pan, X., \& Yan, Y. (2019). Dynamic relationship among environmental regulation, technological innovation and energy efficiency based on large scale provincial panel data in China. Technological Forecasting and Social Change, 144(7), 428-435. https://doi.org/10.1016/j.techfore.2017.12.012

Peng, B., Tu, Y., Elahi, E., \& Wei, G. (2018). Extended Producer Responsibility and corporate performance: Effects of environmental regulation and environmental strategy. Journal of Environmental Management, 218(7), 181-189. https://doi.org/10.1016/j.jenvman.2018.04.068

Piao, S., Li, J., \& Ting, C. (2019). Assessing regional environmental efficiency in China with distinguishing weak and strong disposability of undesirable outputs. Journal of Cleaner Production, 227(22), 748-759. https://doi.org/10.1016/j.jclepro.2019.04.207

Porter, M. E. (1991). Toward a dynamic theory of strategy. Strategic Management Journal, 12(S2), 95117. https://doi.org/10.1002/smj.4250121008

Porter, M. E., \& Linde, C. (1995). Toward a new conception of the environment competitiveness relationship. Journal of Economic Perspectives, 9(5), 97-118. https://doi.org/10.1257/jep.9.4.97

Ren, S., Li, X., Yuan, B., Li, D., \& Chen, X. (2018). The effects of three types of environmental regulation on eco-efficiency: A cross-region analysis in China. Journal of Cleaner Production, 173(4), 245-255. https://doi.org/10.1016/j.jclepro.2016.08.113

Rubashkina, Y., Galeott, M., \& Verdolini, E. (2015). Environmental regulation and competitiveness: empirical evidence on the Porter Hypothesis from European manufacturing sectors. Energy Policy, 83, 288-300. https://doi.org/10.1016/j.enpol.2015.02.014

Shi, X., \& Xu, Z. (2018). Environmental regulation and firm exports: evidence from the eleventh FiveYear Plan in China. Journal of Environmental Economics and Management, 89(2), 187-200. https://doi.org/10.1016/j.jeem.2018.03.003

Song, M., An, Q., Zhang, W., Wang, Z., \& Wu, J. (2012). Environmental efficiency evaluation based on data envelopment analysis: A review. Renewable and Sustainable Energy Reviews, 16(7), 4465-4469. https://doi.org/10.1016/j.rser.2012.04.052

Stern, D. I. (2012). Modeling international trends in energy efficiency. Energy Economics, 34(6), 22002208. https://doi.org/10.1016/j.eneco.2012.03.009

Sueyoshi, T., \& Yuan, Y. (2017). Social sustainability measured by intermediate approach for DEA environmental assessment: Chinese regional planning for economic development and pollution prevention. Energy Economics, 66(8), 154-166. https://doi.org/10.1016/j.eneco.2017.06.008

Suh, S., \& Huppes, G. (2005). Methods for Life Cycle Inventory of a product. Journal of Cleaner Production, 13(7), 687-697. https://doi.org/10.1016/j.jclepro.2003.04.001

Tian, G., Miao, C., Hu, Z., \& Miao, J. (2018). Environmental regulation, local protection and the spatial distribution of pollution-intensive industries in China. Acta Geographica Sinica, 73(10), 1954-1969.

Wang, X., \& Shao, Q. (2019). Non-linear effects of heterogeneous environmental regulations on green growth in G20 countries: Evidence from panel threshold regression. Science of The Total Environment, 660(14), 1346-1354. https://doi.org/10.1016/j.scitotenv.2019.01.094 
Wang, X., Zhang, C., \& Zhang, Z. (2019). Pollution haven or porter? The impact of environmental regulation on location choices of pollution-intensive firms in China. Journal of Environmental Management, 248(20), 109248. https://doi.org/10.1016/j.jenvman.2019.07.019

Wang, Y., \& Shen, N. (2016). Environmental regulation and environmental productivity: The case of China. Renewable and Sustainable Energy Reviews, 62(9), 758-766. https://doi.org/10.1016/j.rser.2016.05.048

Wang, Y., \& Yao, Y. (2001). Source of China’s economic growth, 1952-1999: incorporating human capital accumulation. China Economic Review, 14(1), 32-52. https://doi.org/10.1016/S1043-951X(02)00084-6

Wolff, H. (2014). Keep your clunker in the suburb: Low-emission zones and adoption of green vehicles. The Economic Journal, 124(578), 481-512. https://doi.org/10.1111/ecoj.12091

Yang, Q., \& Liu, H. (2012). Regional heterogeneity and convergence of carbon intensity distribution in China: Based on the empirical research of provincial data between 1995 and 2009. Contemporary Finance \& Economics, (2), 87-98.

Yang, X., He, L., Xia, Y., \& Chen, Y. (2019). Effect of government subsidies on renewable energy investments: The threshold effect. Energy Policy, 132(9), 156-166. https://doi.org/10.1016/j.enpol.2019.05.039

Yu, Y., Huang, J., \& Zhang, N. (2018). Industrial eco-efficiency, regional disparity, and spatial convergence of China’s regions. Journal of Cleaner Production, 204(35), 872-887. https://doi.org/10.1016/j.jclepro.2018.09.054

Zhang, J., Wu, G., \& Zhang, J. (2004). Estimation of China's inter provincial material capital stock: 1952-2000. Economic Research Journal, (10), 35-44.

Zhang, N., Kong, F., \& Choi, Y. (2014). The effect of Size-control policy on unified energy and carbon efficiency for Chinese fossil fuel power plants. Energy Policy, 70(4), 193-200. https://doi.org/10.1016/j.enpol.2014.03.031

Zhang, W., Li, G., Uddin, M. K., \& Guo, S. (2020). Environmental regulation, Foreign investment behavior, and carbon emissions for 30 provinces in China. Journal of Cleaner Production, 248(7), 119-208. https://doi.org/10.1016/j.jclepro.2019.119208

Zhang, Y., Shen, L., Shuai, C., Bian, J., Zhu, M., Tan, Y., \& Ye, G. (2019). How is the environmental efficiency in the process of dramatic economic development in the Chinese cities. Ecological Indicators, 98(3), 349-362. https://doi.org/10.1016/j.ecolind.2018.11.006

Zhang, Z., Xue, B., Chen, X., \& Li, Y. (2015). Convergence in spatial difference of industrial environmental efficiency in China. China Population, Resources and Environment, 25(2), 30-38.

Zhu, Y., \& Wang, Z. (2013). Study on emission reduction control based on R\&D investment under stable economic growth. Studies in Science of Science, 31(04), 554-559.

Zhuo, C., \& Deng, F. (2020). How does China's Western Development Strategy affect regional green economic efficiency. Science of The Total Environment, 707(8), 135939.

https://doi.org/10.1016/j.scitotenv.2019.135939 